\title{
Emergence of carbapenemase-producing Enterobacteriaceae in France, 2004 to 2011
}

S Vaux ${ }^{1}$, A Carbonne ${ }^{2}$, J M Thiolet ${ }^{1}$, V Jarlier ${ }^{3}$, B Coignard (b.coignard@invs.sante.fr) ${ }^{1}$, RAISIN and Expert Laboratories Groups ${ }^{4}$

1. French Institute for Public Health Surveillance (Institut de Veille Sanitaire, InVS), Saint-Maurice, France

2. Centre de coordination de la lutte contre les infections nosocomiales (CClin) Nord, Paris, France

3. Pierre et Marie Curie (Paris 6) University (EA1541), Paris, France

4. The participants of these groups are listed at the end of the article

Vaux S, Carbonne A, Thiolet JM, Jarlier V, Coignard B, RAISIN and Expert Laboratories Groups. Emergence of carbapenemase-producing Enterobacteriaceae in Vaux S, Carbonne A, Thic

Euro Surveill. 2011;16(22):pii=19880. Available online: http://www.eurosurveillance.org/ViewArticle.aspx?Articleld=19880

Emergence of carbapenemase-producing Enterobacteriaceae (CPE) is currently a major public health concern worldwide. This study showed that 53 episodes of CPE infection or colonisation have been notified by French healthcare facilities since 2004 . A sharp increase in the number of notifications was observed in the last three years. Oxacillinase (OXA)48 and Klebsiella pneumoniae carbapenemase (KPC) beta-lactamases were the most frequent enzymes reported in these episodes. The index cases in most episodes were patients with a history of hospitalisation abroad within the previous year. Around a third of the episodes $(n=18)$ led to secondary transmission in hospitals but most of them were controlled due to reinforced measures. Reinforcement of screening and control measures at national level when there is cross-border transfer of patients, along with overall reinforcement of infection control and antimicrobial stewardship worldwide, is urgently needed to contain the spread of CPE.

\section{Introduction}

As Enterobacteriaceae become increasingly resistant to antibiotics, carbapenems are among the few lastline drugs available for therapy against serious infections, such as pyelonephritis or bacteraemia, caused by multidrug-resistant strains, particularly those expressing extended-spectrum beta-lactamases. Resistance to carbapenems, resulting from carbapenemases, reduces the possibility of treating infections of multidrug-resistant strains. Carbapenemase-producing Enterobacteriaceae (CPE) have been reported increasingly worldwide and are becoming a major clinical and public health concern, as they constitute the last step towards a therapeutic dead end.

Carbapenemases belong to three molecular classes of beta-lactamases (A, B and D). Chromosome-encoded class A carbapenemases were first reported in 1994 [1]. The first plasmid-encoded class A carbapenemase, Klebsiella pneumoniae carbapenemase (KPC), was discovered in 1996 and reported for the first time in 2001 from the United States in a K. pneumoniae clinical isolate [2]. Since then, KPC-producing isolates have spread worldwide, notably in Greece and Israel, where they are now endemic $[3,4]$. The metallo-beta-lactamases (class B), such as Verona integron-encoded metallo-betalactamase (VIM) and imipenemase (IMP), are currently prevalent in Greece, Italy, Japan and Spain. Belonging to the same class, New Dehli metallo-beta-lactamase (NDM)-1 has recently emerged in India, Pakistan and the United Kingdom [5,6]. NDM-1 represents a serious threat of rapid dissemination of multiple antibiotic resistance since the majority of NDM 1-producing Enterobacteriaceae have been reported to remain susceptible only to colistin and tigecycline [5]. The first of the class D beta-lactamases with carbapenemase activity was described in 1995 [1]. Among this class, oxacillinase (OXA)-48, which was discovered in a clinical $K$. pneumoniae isolate in 2004 , has been identified mostly in Mediterranean countries, especially Turkey $[1,7]$.

In France, resistance of Enterobacteriaceae to carbapenems remains uncommon. According to data from the European Antimicrobial Resistance Surveillance Network (EARS-Net), the proportion of carbapenemresistant strains among strains isolated from patients with invasive infections in 2009 was $0.03 \%$ (2 of 7,731) for Escherichia coli and $0.16 \%$ (2 of 1,268) for $K$. pneumoniae [8]. However, CPE isolates have already been described in France and were involved in sporadic cases or limited outbreaks [3,9-15].

Since 2001, a national Healthcare-Associated Infections Early Warning and Response System (HAI-EWRS) has been implemented in France to quickly detect unusual and emerging events in hospitals, promote outbreak investigations and implement control measures [16]. Healthcare facilities are mandatorily obliged to notify such events to interregional infection control coordinating centres (CClins), so they can receive technical assistance and to regional health authorities for the follow up of control measures. Notifications are then forwarded to the French Institute for Public Health 
Surveillance (Institut de Veille Sanitaire, InVS) for second-line assistance and the monitoring of trends. For microbiological expertise, healthcare facilities can rely on a network of national reference centres (NRCs), funded and coordinated by InVS [17] or expert laboratories located in major university hospitals or research centres.

The objectives of this study were to review, quantify and describe the characteristics of CPE episodes reported to InVS during February 2004 (when the first CPE cases were notified) to 11 April 2011.

\section{Methods}

\section{Definitions}

We defined a case as a patient infected or colonised by a CPE that was confirmed by a reference or expert laboratory. The clinical diagnosis of infection or colonisation was made by the physician in charge of the patient.

An episode was defined as one sporadic case or several cases related by an identified chain of transmission. A chain of transmission was established between two or more cases if they had been in contact, i.e. they shared the same healthcare workers (nurse, auxiliary staff or physician).

\section{Epidemiological investigation}

We included all the episodes that were notified by healthcare facilities through the French HAI-EWRS. We also included other episodes that were retrospectively identified through a survey of French microbiologists known to have an interest and expertise in Enterobacteriaceae beta-lactamases, conducted by InVS by email in August 2010. Follow-up data on each notified episode were provided to InVS by CClins or laboratories.

For each episode, we documented the patients' demographic characteristics, number of infected or colonised patients, site of infection/colonisation, number of reported deaths, bacterial species, types of carbapenemase (as identified by the Antimicrobial Resistance NRC, based at the Institut Pasteur in Paris, or expert laboratories), existence of an epidemiological link between the index case and a foreign country, name of this country and the nature of the link (previous stay or hospitalisation abroad within one year of hospitalisation in France).

\section{Microbiological investigations}

Antibiotic susceptibility was tested by disc diffusion on Mueller-Hinton agar according to standards of the Antibiogram Committee of the French Microbiology Society [18].

In carbapenem-resistant strains, carbapenemase production was detected using Hodge test, and synergy test between carbapenems and ethylenediaminetetraacetic acid (EDTA) (for class B metallo beta-lactamases) or clavulanic acid (for class A beta-lactamases) [19]. The genes encoding carbapenemases were identified by the Antimicrobial Resistance NRC or 13 expert laboratories using PCR and sequencing of the amplified product [20]. In every PCR analysis, a positive control strain was included. All expert laboratories were located in major university hospitals or research centres and were involved in external quality assessment at the national level (through the French Health Products Safety Agency, Afssaps) or international level (through EARS-Net). The Antimicrobial Resistance NRC follows Institut Pasteur quality control policies.

\section{FIGURE}

Monthly number of episodes of carbapenemase-producing Enterobacteriaceae infection or colonisation, France,

1 January 2004-11 April $2011(\mathrm{n}=53)$

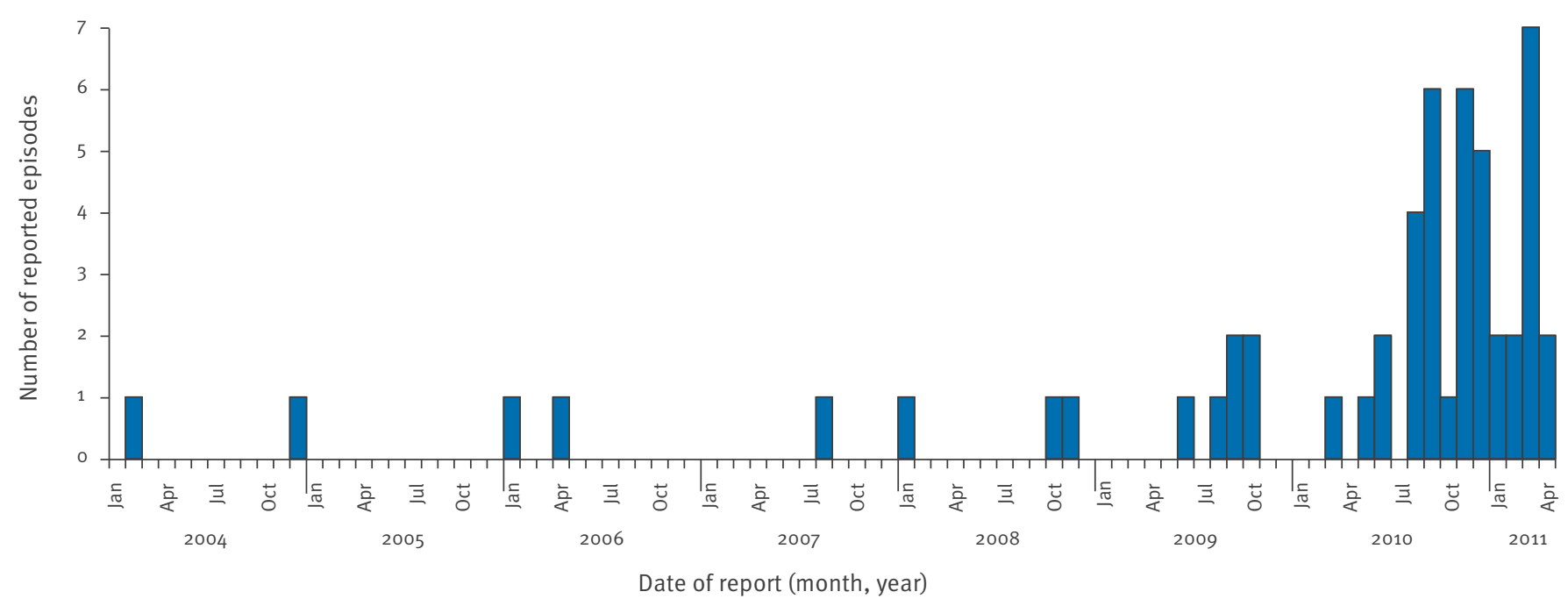




\section{Results}

Number and location of CPE episodes

The first reported CPE episode occurred in France in February 2004 [12]. The yearly number of episodes remained low (1-3 episodes) until 2009, when a sharp increase was observed: 6,26 and 13 episodes in 2009, 2010 and the first four months of 2011, respectively (Figure). A total of 53 CPE episodes were identified in France between February 2004 and April 2011, most of which $(n=50)$ were reported through the HAI-EWRS.

These 53 episodes were reported in the following areas of France: Paris and the north of the country $(n=36)$, south-east $(n=8)$, east $(n=4)$, west $(n=3)$ and southwest $(n=2)$.

\section{Bacteria and resistance mechanisms}

The CPE that were reported were mainly $K$. pneumoniae ( $\mathrm{n}=33$ episodes), but also $E$. coli $(\mathrm{n}=14)$, Enterobacter cloacae $(\mathrm{n}=6)$, Enterobacter aerogenes $(n=3)$, Citrobacter freundii $(n=2)$, Serratia marcescens $(n=1)$ or Proteus mirabilis $(n=1)$. Two or three species of Enterobacteriaceae were isolated in six episodes.

The carbapenemases involved in the 53 episodes were OXA-48 $(n=23)$, KPC $(n=16)$, VIM $(n=6), N D M-1(n=7)$ and VIM plus IMP $(n=1)$ (Table 1).

\section{Epidemiological description}

of the CPE episodes

The 53 episodes accounted for a total of 169 cases, comprising 52 infections and 112 colonisations (data available for 164 cases). Among the 169 cases, 43 deaths were reported, giving an estimated crude lethality rate (deaths of all cases, whether infected or colonised) of $25 \%$.
Of the 53 episodes, 36 included a single, sporadic case. Secondary cases were reported in 18 episodes: the total number of cases in these 18 episodes ranged from 2 (in six episodes) to 32 (one episode). The mean number of cases by cluster was seven (median: four cases).

A total of 54 index cases were identified. In one episode, two co-index cases (two members of the same family repatriated at the same time) were reported. Of the 54 index cases with available information, 37 were found to be colonised, at least at one site: digestive tract $(n=27$ episodes), urinary tract $(n=5)$, skin $(n=2)$, respiratory tract $(n=3)$ abdominal tract $(n=1)$ or gynaecological tract $(n=1)$. A total of 16 were infected at least at one site: urinary tract $(n=6)$, respiratory tract $(n=3)$, abdominal or gastrointestinal tract $(n=5)$, bloodstream $(n=3)$ and skin or soft tissue $(n=1)$. The clinical diagnosis of infection or colonisation was not available for one index case and the clinical site was not available for two colonised and one infected index cases.

\section{Episodes of particular importance}

Several episodes were of particular importance, considering their impact on healthcare activities. In 2004, an outbreak of eight cases with VIM-1-producing $K$. pneumoniae (including five infections) occurred after the transfer of a patient from a Greek hospital. This outbreak, which lasted six months, was finally controlled after implementation of extended control and screening measures and led to the screening of 277 contactpatients $[9,12]$. In 2009, 13 cases with KPC-producing K. pneumoniae (two infections) were associated with a contaminated endoscope and transmission from patient to patient during healthcare in three hospitals. Controlling this outbreak also required implementation of extended control and screening measures and led to

\section{TABLE 1}

Bacterial species and carbapenemase type in 53 episodes of carbapenemase-producing Enterobacteriaceae infection or colonisation, France, 1 January 2004-11 April 2011

\begin{tabular}{|c|c|c|c|c|c|c|}
\hline \multirow{2}{*}{ Bacterial species } & \multicolumn{5}{|c|}{ Number of episodes by type of carbapenemase } & \multirow[b]{2}{*}{ Total } \\
\hline & OXA-48 & $\mathrm{KPC}$ & NDM-1 & VIM & VIM and IMP & \\
\hline Klebsiella pneumoniae & 12 & 14 & 3 & 4 & 0 & 33 \\
\hline Escherichia coli & 9 & 1 & 3 & 1 & 0 & 14 \\
\hline Enterobacter cloacae & 4 & 1 & 0 & 1 & 0 & 6 \\
\hline Enterobacter aerogenes & 2 & 0 & 0 & 0 & 1 & 3 \\
\hline Citrobacter freundii & 1 & 0 & 1 & 0 & 0 & 2 \\
\hline Proteus mirabilis & 0 & 0 & 1 & 0 & 0 & 1 \\
\hline Serratia marcescens & 1 & 0 & 0 & 0 & 0 & 1 \\
\hline Total & $23^{a}$ & 16 & $7^{\mathrm{b}}$ & 6 & 1 & $53^{c}$ \\
\hline
\end{tabular}

IMP: imipenemase; KPC: Klebsiella pneumoniae carbapenemase; NDM: New Dehli metallo-beta-lactamase: OXA: oxacillinase; VIM: Verona integron-encoded metallo-beta-lactamase.

a OXA-48 was involved in four episodes with two bacterial species and in one episode with three species.

${ }^{b}$ NDM-1 was involved in one episode with two bacterial species isolated from patients with a possible epidemiological link.

' Five episodes involved two species with the same carbapenemase and one episode involved three species with the same carbapenemase. 
the screening of 341 contact-patients in five healthcare facilities. The index case was a patient transferred from Greece $[14,21]$. In 2010 , an outbreak of 13 cases with OXA-48-producing $K$. pneumoniae (seven infections) led to the screening of more than 280 contact-patients in 15 healthcare facilities. Interestingly, the index case in this episode did not report any travel abroad [22]. In addition, an ongoing episode of OXA-48-producing K. pneumoniae, which was notified in November 2010, has included 32 cases (infections or colonisations) to date and has led to the screening of contact-patients in more than 10 healthcare facilities.

Seven episodes were associated with NDM-1-mediated carbapenem-resistance: five were reported in 2010 and two during the first three months of 2011. In these seven episodes, there were six index cases who reported travel within the previous year to India and one to Iraq [23-25]. Five were hospitalised abroad before their transfer to a French hospital. Two lived in India and had received healthcare in France, but had no reported hospitalisation in India within the previous year. Nine cases were associated with these episodes; the bacterial species involved are reported in Table 1. No deaths were reported.

\section{Association with cross-border transfer}

Of the 53 episodes, 42 were associated with crossborder transfers: the index cases had been transferred directly from a foreign hospital to a French hospital $(n=27$ episodes), or had been hospitalised in a foreign hospital a few days $(n=1)$, a few weeks $(n=1)$, between one and six months $(n=4)$ or one year $(n=1)$ before their hospitalisation in France. In three additional episodes, the index cases lived abroad and had no reported hospitalisation in the previous year (two of the index cases were colonised; the other was infected). In the other five episodes, the index cases had spent weeks or months in a foreign country before their hospitalisation in France, but without any reported hospitalisation abroad. These five index cases were colonised.

In the 42 episodes associated with cross-border transfers, the countries where index cases had travelled, been hospitalised or had lived were Greece $(n=14$ episodes), Morocco $(n=7)$, India $(n=6)$, Italy $(n=4)$, Algeria $(n=3)$, Tunisia $(n=2)$, Egypt $(n=2)$, Turkey $(n=2)$, United States $(n=1)$ and Iraq $(n=1)$. Of the 14 episodes involving cross-border transfer with North Africa (Morocco, Algeria, Tunisia and Egypt), 12 were associated with OXA-48-producing bacteria (Table 2 ).

In 11 of the 53 episodes, the index cases had not travelled, been hospitalised or lived in a foreign country, before their hospitalisation in France. Among these index cases, one was reported from Réunion. The majority of these episodes $(n=9)$ were associated with OXA-48 carbapenemase (Table 2 ).

\section{Discussion and conclusion}

Although national surveillance data demonstrate that Enterobacteriaceae resistance to carbapenems remains rare in France, our study, based on HAI-EWRS notifications and a survey among French microbiologists, strongly suggests that CPE are emerging in French healthcare facilities and have an important impact on the organisation of health care. It also demonstrates the ability of the French HAI-EWRS to detect unusual and emerging events in hospitals, since a large majority of CPE episodes have been reported through this

\section{TABLE 2}

Carbapenemase type in 53 episodes of carbapenemase-producing Enterobacteriaceae infection or colonisation, France, 1 January 2004-11 April 2011, by country where index cases had been hospitalised or stayed abroad

\begin{tabular}{|c|c|c|c|c|c|c|}
\hline \multirow{2}{*}{ Country } & \multicolumn{5}{|c|}{ 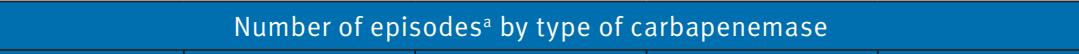 } & \multirow{2}{*}{ Total } \\
\hline & OXA-48 & KPC & NDM-1 & VIM & VIM and IMP & \\
\hline Greece & 0 & $11(2007)$ & 0 & $3(2004)$ & 0 & 14 \\
\hline Morocco & $7(2010)$ & 0 & o & 0 & o & 7 \\
\hline India & 0 & 0 & $6(2010)$ & o & 0 & 6 \\
\hline Italy & o & $2(2010)$ & 0 & $2(2008)$ & o & 4 \\
\hline Algeria & 1 (2010) & 1 (2010) & 0 & $1(2008)$ & 0 & 3 \\
\hline Tunisia & $2(2011)$ & 0 & o & 0 & o & 2 \\
\hline Egypt & $2(2009)$ & o & 0 & 0 & 0 & 2 \\
\hline Turkey & $2(2010)$ & 0 & o & 0 & o & 2 \\
\hline Iraq & 0 & 0 & $1(2010)$ & 0 & 0 & 1 \\
\hline United States & 0 & $1(2006)$ & 0 & 0 & 0 & 1 \\
\hline $\begin{array}{l}\text { No stay or hospitalisation } \\
\text { abroad reported }\end{array}$ & 9 (2010) & $1(2010)$ & 0 & 0 & $1(2004)$ & 11 \\
\hline Total & 23 & 16 & 7 & 6 & 1 & 53 \\
\hline
\end{tabular}

IMP: imipenemase; KPC: Klebsiella pneumoniae carbapenemase; NDM: New Dehli metallo-beta-lactamase: OXA: oxacillinase; VIM: Verona integron-encoded metallo-beta-lactamase.

a The years in parentheses are the year the first case in this study was reported. 
system. The effectiveness of HAI-EWRS has also been demonstrated with other emerging pathogens in the recent past [26-28].

In this survey of CPE episodes notified in France, most of the reported episodes comprised sporadic cases and were related to cross-border transfer, mainly after hospitalisation in countries abroad where CPE are endemic. OXA-48 was the most frequent type of carbapenemase and was often associated with index cases who had been previously hospitalised in North Africa and Turkey. The second most frequent carbapenemase was KPC, which was often associated with index cases previously hospitalised in Greece. The types of carbapenemase observed by country of origin for index cases are highly consistent with those previously described in these countries: NDM-1 in the Indian subcontinent $[5,23]$, KPC notably in Greece and the United States [3,4], OXA-48 in Turkey [29,30], Tunisia [31] and Morocco [32]. In Greece, the proportion of carbapenemresistant strains among $K$. pneumoniae increased from $27.8 \%$ to $43.5 \%$ during 2005 to 2009 [8]. Interestingly, the origin of index cases was also highly consistent with population migration routes and countries most frequently visited by French tourists [33].

As cross-border transfer and globalisation are major trends in the world today, awareness of the risk of spread of multidrug resistance, such as carbapemenase-mediated resistance of Enterobacteriaceae by cross-border transfer of patients, needs to be emphasised. Furthermore, appropriate control measures need to be strongly reinforced in countries where carbepenemase-producing Enterobacteriaceae are endemic $[34,35]$. In addition, in order to prevent or to delay emergence of carbapenemase-mediated resistance in countries with low prevalence, such as France, it is essential to rapidly identify CPE by screening carriers among patients transferred from hospitals in countries with high prevalence of these organisms and to implement adequate control measures.

In response to the trends observed, the French Healthcare Safety Advisory Committee issued in 2010 national recommendations for screening and presumptive isolation with contact precautions of patients transferred from or hospitalised abroad. These recommendations target two multidrug-resistant pathogens with a low prevalence in France (vancomycin-resistant enterococci, VRE, and (PE). Healthcare facilities are requested to notify immediately CClins and regional health authorities about any suspected episodes of VRE or CPE infection/colonisation and laboratories should send strains to the Antimicrobial Resistance NRC or an expert laboratory for confirmation [36]. If a case is confirmed, adequate control measures should be rapidly implemented: reinforcement of standard and contact precautions, contact tracing and cohorting of patients into three distinct sectors (one for cases, one for contact-patients and one for newly admitted VREor CPE-free patients) $[36,37]$. Such a strict strategy of cohorting patients - which had been developed and field-tested in healthcare facilities that experienced the first CPE outbreaks and was later disseminated through national recommendations - has limited the number of secondary cases and has led to the control of CPE outbreaks $[9,21]$.

In 11 of the 53 reported episodes, the index cases had not crossed any border. Nine of the 11 were due to OXA-48 carbapenemase. Although a chain of transmission resulting from contact with an unknown traveller from abroad could have been missed, the beginning of autochthonous circulation of CPE in France cannot be excluded. Almost all of these 11 episodes $(n=10)$ have been reported since 2010: this recent trend emphasises the need for sustained vigilance when carbapenem resistance is suspected in Enterobacteriaceae isolated from any patient. Moreover, it also underlines the need for better antimicrobial stewardship in France. In French healthcare facilities, carbapenem consumption increased from 2.0 defined daily doses per 1,000 bed-days in 1999 to 4.8 per 1,000 in 2009 (P. Cavalié, Afssaps, personal communication, November 2010) and is most probably related to the spread of Enterobacteriaceae producing extended-spectrum beta-lactamases [8].

Our study has some limitations. First, the completeness of reporting cannot be guaranteed since (i) all French healthcare facilities do not have the capacity to identify patients with CPE and should therefore rely on the help of the Antimicrobial Resistance NRC or an expert laboratory, (ii) some healthcare facilities may not report them (despite reporting being mandatory and strongly encouraged) and (iii) data collected through HAI-EWRS could be incomplete. Conversely, recent emphasis on CPE in the scientific literature, national recommendations and media reports could have triggered better reporting and may partly explain the sharp increase in the number of reported episodes observed in 2010.

Second, the impact of CPE on patients' morbidity or mortality is difficult to assess. The crude mortality rate of cases in this study was high, as was reported in outbreaks with extended-spectrum beta-lactamaseproducing Enterobacteriaceae [38,39]. However, crude estimates of lethality are not easy to interpret because of the difficulties in ascertaining retrospectively the cause of deaths in patients with multiple pathologies, and as it is not known whether the patients who died had been infected or colonised.

Last, six episodes involved more than one bacteria species with the same resistance mechanism, but no microbiological data were available that could account for this. Such bacteria could have been identified among the same or different patients and, as reported previously, interspecies transmission of carbapenemase genes by transposons or by self-transferable plasmids could have occurred [40]. 
Improving coordination between the Antimicrobial Resistance NRC and expert laboratories, healthcare facilities and InVS in the surveillance of CPE should allow episodes to be better documented, future trends to be monitored and the impact of current national recommendations to be assessed.

In conclusion, emergence of CPE in France, Europe and worldwide is nowadays a major medical and public health concern because it may lead to therapeutic dead-ends. The French HAI-EWRS demonstrated to be an effective tool to detect and monitor CPE emergence and to promote adequate recommendations for control. To date, most of episodes reported in France have been associated with a sporadic case who had been hospitalised, had travelled or had lived in foreign countries where CPE are prevalent.

The need to contain CPE emergence in France justifies reinforcing control measures when there is cross-border transfer. However, such measures might have a limited impact in the long term if no similar measures are implemented to control the sources abroad. Increasing laboratories' capacities, infection control and antimicrobial stewardship at a global level is therefore urgently needed for a successful fight against this new type of antimicrobial resistance.

\section{Acknowledgments}

We thank all healthcare professionals, infection control units, healthcare facilities and microbiological laboratories involved in the study, Patrice Nordmann (Service de Bactériologie-Virologie-Hygiène, Inserm U914, Le KremlinBicêtre) for strain characterisation in some of the episodes notified by healthcare facilities and Philippe Cavalié (Afssaps) for national data on carbapenem consumption.

RAISIN (Réseau d'alerte, d'investigation et de surveillance des infections nosocomiales) Group participants

S. Alleaume (InVS, Saint-Maurice), C. Bernet (CClin Sud-Est, Lyon), I. Poujol (InVS, Saint-Maurice), H. Sénéchal (CClin Ouest, Rennes), L. Simon (CClin Est, Nancy), AG. Venier (CClin Sud-Ouest, Bordeaux).

\section{Expert Laboratories Group participants}

A. Andremont (Antimicrobial Resistance National Reference Centre, Resistance in commensal flora Associated Laboratory, Hôpital Bichat, Paris), G. Arlet (Laboratoire de Bactériologie, Pierre et Marie Curie (Paris 6) University, Paris), R. Bonnet (Laboratoire de Microbiologie, Centre Hospitalier Universitaire, Clermont-Ferrand), C. de Champs (Laboratoire de Microbiologie, Centre Hospitalier Universitaire, Reims), S. Corvec (Laboratoire de Microbiologie, Centre Hospitalier Universitaire, Nantes), P. Courvalin (Antimicrobial Resistance National Reference Centre, Institut Pasteur, Paris), K. Jeannot (Antimicrobial Resistance National Reference Centre, Institut Pasteur, Paris), J.P. Lavigne (Laboratoire de Microbiologie, Centre Hospitalier Universitaire, Nîmes), A. Lozniewski (Laboratoire de Microbiologie, Centre Hospitalier Universitaire, Nancy), M.H. Nicolas-Chanoine (Service de Microbiologie, Hôpital Beaujon, Clichy), I. Podglajen (Service de Microbiologie, Hôpital Européen Georges Pompidou, Paris), C. Quentin (Laboratoire de Microbiologie, Université de Bordeaux 2 - UMR CNRS 5234, Bordeaux), J.M. Rolain (URMITE CNRS-IRD UMR 6236, Faculté de Médecine et de
Pharmacie, Marseille), W. Sougakoff (INSERM UMRS 872-12, Pierre et Marie Curie (Paris 6) University, Paris).

\section{References}

1. Queenan AM, Bush K. Carbapenemases: the versatile betalactamases. Clin Microbiol Rev. 2007(3);20:440-58.

2. Yigit H, Queenan AM, Anderson GJ, Domenech-Sanchez A, Biddle JW, Steward CD, et al. Novel carbapenem-hydrolyzing beta-lactamase, KPC-1, from a carbapenem-resistant strain of Klebsiella pneumoniae. Antimicrob Agents Chemother. 2001;45(4):1151-61.

3. Nordmann P, Cuzon G, Naas T. The real threat of Klebsiella pneumoniae carbapenemase-producing bacteria. Lancet Infect Dis. 2009;9(4):228-36.

4. Pournaras S, Protonotariou E, Voulgari E, Kristo I, Dimitroulia E, Vitti D, et al. Clonal spread of KPC-2 carbapenemaseproducing Klebsiella pneumoniae strains in Greece. Antimicrob Chemother. 2009;64(2):348-52.

5. Kumarasamy KK, Toleman MA, Walsh TR, Bagaria J, Butt F, Balakrishnan R, et al. Emergence of a new antibiotic resistance mechanism in India, Pakistan, and the UK: a molecular, biological, and epidemiological study. Lancet Infect Dis. 2010(9);10:597-602.

6. Yong D, Toleman MA, Giske CG, Cho HS, Sundman K, Lee K, et al. Characterization of a new metallo-beta-lactamase gene, bla(NDM-1), and a novel erythromycin esterase gene carried on a unique genetic structure in Klebsiella pneumoniae sequence type 14 from India. Antimicrob Agents Chemother. 2009;53(12):5046-54

7. Poirel L, Naas T, Nordmann P. Diversity, epidemiology, and genetics of class D beta-lactamases. Antimicrob Agents Chemother. 2010;54(1):24-38.

8. European Centre for Disease Prevention and Control (ECDC). Antimicrobial resistance surveillance in Europe 2009. Annual Report of the European Antimicrobial Resistance Surveillance Network (EARS-Net). Stockholm: ECDC; 2010. Available from: http://ecdc.europa.eu/en/publications/Publications/Forms/ ECDC_DispForm.aspx?ID $=580$

9. Kassis-Chikhani N, Saliba F, Carbonne A, Neuville S, Decre $D$, Sengelin C, et al. Extended measures for controlling an outbreak of VIM-1 producing imipenem-resistant Klebsiella pneumoniae in a liver transplant centre in France, 2003-2004. Euro Surveill. 2010;15(46):pii=19713. Available from: http:// www.eurosurveillance.org/ViewArticle.aspx?Articleld=19713

10. Barbier F, Ruppé E, Giakkoupi P, Wildenberg L, Lucet J, Vatopoulos A, et al. Genesis of a KPC-producing Klebsiella pneumoniae after in vivo transfer from an imported Greek strain. Euro Surveill. 2010;15(1):pii=19457. Available from: http://www.eurosurveillance.org/ViewArticle. aspx?Articleld $=19457$

11. Biendo M, Canarelli B, Thomas D, Rousseau F, Hamdad F, Adjide C, et al. Successive emergence of extended-spectrum beta-lactamase-producing and carbapenemase-producing Enterobacter aerogenes isolates in a university hospital. J Clin Microbiol. 2008;46(3):1037-44.

12. Kassis-Chikhani N, Decré D, Gautier V, Burghoffer B, Saliba F, Mathieu D, et al. First outbreak of multidrug-resistant Klebsiella pneumoniae carrying blaVIM-1 and blaSHV-5 in a French university hospital. J Antimicrob Chemother. 2006;57(1):142-5.

13. Kassis-Chikhani N, Decré D, Ichai P, Sengelin C, Geneste $D$, Mihaila L, et al. Outbreak of Klebsiella pneumoniae producing KPC-2 and SHV-12 in a French hospital. J Antimicrob Chemother. 2010;65(7):1539-40.

14. Naas T, Cuzon G, Babics A, Fortineau N, Boytchev I, Gayral $\mathrm{F}$, et al. Endoscopy-associated transmission of carbapenem resistant Klebsiella pneumoniae producing KPC-2 betalactamase. J Antimicrob Chemother. 2010;65(6):1305-6.

15. Petrella S, Ziental-Gelus N, Mayer C, Renard M, Jarlier $V$, Sougakoff W. Genetic and structural insights into the dissemination potential of the extremely broad-spectrum class A beta-lactamase KPC-2 identified in an Escherichia coli strain and an Enterobacter cloacae strain isolated from the same patient in France. Antimicrob Agents Chemother. 2008(10);52:3725-36.

16. The RAISIN Working Group. "RAISIN" - a national programme for early warning, investigation and surveillance of healthcare-associated infection in France. Euro Surveill. 2009;14(46):pii=19408. Available from: http://www. eurosurveillance.org/ViewArticle. aspx?Articleld $=19408$ 
17. Institut de Veille Sanitaire (InVS). Centres nationaux de référence (CNR). [National Reference Centres (NRC)]. SaintMaurice: InVS. French. [Accessed 26 May 2011]. Available from : http://www.invs.sante.fr/surveillance/cnr/

18. Société Française de Microbiologie (SFM). Comité de l'antibiogramme de la Société Française de Microbiologie. Recommandations 2011 [Antibiogram committee of the French Society for Microbiology. Recommendations 2011]. Paris: SFM: 2011. French.

19. Picão RC, Andrade SS, Nicoletti AG, Campana EH, Moraes GC, Mendes RE, et al. Metallo-beta-lactamase detection: comparative evaluation of double-disk synergy versus combined disk tests for IMP-, GIM-, SIM-, SPM-, or VIMproducing isolates. J Clin Microbiol. 2008;46(6):2028-37.

20. Courvalin P, Leclercq R, Rice LB, editors. Antibiogram. Washington DC: American Society for Microbiology Press: 2010.

21. Carbonne A, Thiolet JM, Fournier S, Fortineau N, KassisChikhani N, Boytchev I, et al. Control of a multi-hospital outbreak of KPC-producing Klebsiella pneumoniae type 2 in France, September to October 2009. Euro Surveill. 2010;15(48):pii=19734. Available from: http://www. eurosurveillance.org/ViewArticle.aspx?Articleld =19734

22. Cuzon G, Ouanich J, Gondret R, Naas T, Nordmann P. Outbreak of OXA-48-positive carbapenem-resistant Klebsiella pneumoniae isolates in France. Antimicrob Agents Chemother. 2011;55(5):2420-3.

23. Struelens MJ, Monnet DL, Magiorakos AP, Santos O'Connor F, Giesecke J, European NDM-1 Survey Participants. New Delhi metallo-beta-lactamase 1-producing Enterobacteriaceae: emergence and response in Europe. Euro Surveill. 2010;15(46):pii=19716. Available from: http://www. eurosurveillance.org/ViewArticle.aspx?Articleld=19716

24. Poirel L, Fortineau N, Nordmann P. International transfer of NDM-1-producing Klebsiella pneumoniae from Iraq to France. Antimicrob Agents Chemother. 2011;55(4):1821-2.

25. Poirel L, Ros A, Carricajo A, Berthelot P, Pozzetto B, Bernabeu $\mathrm{S}$, et al. Extremely drug-resistant Citrobacter freundii isolate producing NDM-1 and other carbapenemases identified in a patient returning from India. Antimicrob Agents Chemother. 2011;55(1):447-8.

26. Bourdon N, Fines-Guyon M, Thiolet JM, Maugat S, Coignard $B$, Leclercq $R$, et al. Changing trends in vancomycin-resistant enterococci in French hospitals, 2001-08. J Antimicrob Chemother. 2011;66(4):713-21.

27. Coignard B, Barbut F, Blanckaert K, Thiolet JM, Poujol I, Carbonne A, et al. Emergence of Clostridium difficile toxinotype III, PCR-ribotype 027-associated disease, France, 2006. Euro Surveill. 2006;11(37):pii=3044. Available from: http://www.eurosurveillance.org/ViewArticle. aspx?Articleld $=3044$

28. Naas T, Coignard B, Carbonne A, Blanckaert K, Bajolet O, Bernet $C$, et al. VEB-1 Extended-spectrum beta-lactamaseproducing Acinetobacter baumannii, France. Emerg Infect Dis. 2006;12(8):1214-22.

29. Carrër A, Poirel L, Eraksoy H, Cagatay AA, Badur S, Nordmann P. Spread of OXA-48-positive carbapenem-resistant Klebsiella pneumoniae isolates in Istanbul, Turkey. Antimicrob Agents Chemother. 2008;52(8):2950-4.

30. Carrër A, Poirel L, Yilmaz M, Akan OA, Feriha C, Cuzon G, et al. Spread of OXA-48-encoding plasmid in Turkey and beyond Antimicrob Agents Chemother. 2010;54(3):1369-73.

31. Cuzon G, Naas T, Lesenne A, Benhamou M, Nordmann P. Plasmid-mediated carbapenem-hydrolysing OXA-48 betalactamase in Klebsiella pneumoniae from Tunisia. Int Antimicrob Agents. 2010;36(1):91-3.

32. Benouda A, Touzani O, Khairallah MT, Araj GF, Matar GM. First detection of oxacillinase-mediated resistance to carbapenems in Klebsiella pneumoniae from Morocco. Ann Trop Med Parasitol. 2010;104(4):327-30.

33. Ministère de l'économie des finances et de l'industrie. Voyages personnels. Répartition des voyages et nuitées personnels à l'étranger par pays de destination (2008). [Personal travel. Distribution of personal trips and overnight stays abroad by country of destination (2008)]. 2009. French. Available from: http://www.tourisme.gouv.fr/stat_etudes/memento/2009/p83. pdf

34. Coignard B. Cross-border transfer of patients with multidrugresistant microorganisms in Europe [abstract 704]. Fifth Decennial International Conference on Healthcare-Associated Infections 2010, Atlanta, GA, 18-22 Mar 2010.

35. Wernli D, Haustein T, Conly J, Carmeli Y, Kickbusch I, Harbarth S. A call for action: the application of the international health regulations to the global threat of antimicrobial resistance. PLoS Med. 2011;8(4):e1001022.
36. Haut Conseil de la Santé Publique. Commission spécialisée Sécurité des patients: infections nosocomiales et autres évènements indésirables liés aux soins et aux pratiques. Maîtrise de la diffusion des bactéries multirésistantes aux antibiotiques importées en France par des patients rapatriés ou ayant des antécédents d'hospitalisation à l'étranger [Control of multidrug-resistant bacteria imported into France from patients repatriated or with a history of hospitalisation abroad]. Nov 2010. French. Available from: http://www.hcsp.fr/ docspdf/avisrapports/hcspr20101116_bmrimport.pdf

37. Haut Conseil de la santé publique. Commission spécialisée Sécurité des patients: infections nosocomiales et autres évènements indésirables liés aux soins et aux pratiques. Rapport relatif à la maîtrise de l'émergence et de la diffusion des entérocoques résistants aux glycopeptides (ERG) dans les établissements de santé français [Control of the emergence of glycopeptide-resistant enterococci in French healthcare facilities]. March 2010. French. Available from: http://www. hcsp.fr/docspdf/avisrapports/hcspr20090219_ERG.pdf

38. Patel G, Huprikar S, Factor SH, Jenkins SG, Calfee DP. Outcomes of carbapenem-resistant Klebsiella pneumoniae infection and the impact of antimicrobial and adjunctive therapies. Infect Control Hosp Epidemiol. 2008;29(12):1099-106.

39. Ramphal R, Ambrose PG. Extended-spectrum beta-lactamases and clinical outcomes: current data. Clin Infect Dis. 2006;42 Suppl 4:S164-72.

40. Drieux L, Bourgeois-Nicolaos N, Cremmiter J, Lawrence C, Jarlier V, Doucet-Populaire F, et al Accumulation of carbapenemase producing Gram-negative bacteria in a single patient linked to the acquisition of multiple carbapenemase producers and to the vivo transfer of plasmid encoding VIM-1. Int J Antimicrob Agents. 2011 May 12. [Epub ahead of print]. 